\title{
PRAZER ESTÉTICO E CONTROLE EMOCIONAL OU CAUSA DO DESEJO DE STATUS: O DISCURSO DA MERITOCRACIA SOCIAL E O CONSUMIDOR HEDONISTA
}

\author{
ROSANE DA CONCEIÇÃO PEREIRA ${ }^{1}$ \\ Universidade Salgado de Oliveira, Curso de Comunicação Social, Universo Niterói \\ R. Mal. Deodoro, 263 - 24030-060 - Centro - Niterói -RJ - Brasil \\ rosadosoldyahoo.com.br
}

\begin{abstract}
Resumo. $O$ artigo é uma análise dos aspectos motivacionais ao consumo. Enfatiza as relações entre a busca de prazer e de controle emocional pela prática de consumo da arte e de outros na perspectiva de Colin Campbell. Trata-se também de uma crítica ao discurso político que afirma a meritocracia como causa do desejo de status na visão de Alain de Botton.
\end{abstract}

Palavras-chave: consumo; discurso; meritocracia.

\begin{abstract}
The article is an analysis of the motivational aspects to the consumption. Emphasizes the relations between the pursuit of pleasure and emotional control by the practice of consumption of art and others in the perspective of Colin Campbell. It is also a critique of the political discourse that affirms meritocracy as the cause of the desire for status in Alain de Botton's view.
\end{abstract}

Keywords: consumption; discourse; meritocracy.

\section{INTRODUZINDO A QUESTÃO}

\begin{abstract}
Com a ascensão de uma meritocracia econômica, os pobres deixaram de ser descritos, em alguns setores, como 'desafortunados', alvo da caridade e da culpa dos ricos, e passaram a ser descritos como 'fracassados', alvo justo de desprezo aos olhos de indivíduos fortes que se fizeram sozinhos, que não eram inclinados a sentir vergonha de suas mansões nem choravam lágrimas de crocodilo por aqueles de cuja companhia eles escaparam. (BOTTON, 2005, p. 89)
\end{abstract}

Afinal, o que há de positivo e de negativo na meritocracia do sujeito na sociedade, e o que esses aspectos significam no discurso político (PÊCHEUX, 1995) que a afirma para o consumidor hedonista, na sociedade de consumo do prazer, do controle emocional e do desejo de status? Para problematizar essa questão é preciso recorrer à proveniência da estrutura meritocrática da sociedade. Durante os séculos XIX e XX

\footnotetext{
${ }^{1}$ Doutora em Linguística (UFF). Docente no ensino superior de Comunicação Social (UNIVERSO Niterói) e no ensino médio-técnico integrado em Publicidade e em Marketing da Escola Técnica Estadual Adolpho Bloch da Fundação de Apoio à Escola Técnica (ETEAB-FAETEC). Pesquisadora CNPq e FAPERJ.
} 
constitui-se a ideologia da sociedade meritocrática, na qual as classes menos abastadas, se tivessem talento, energia e habilidade, poderiam chegar ao topo da hierarquia social.

Para o malsucedido ficou mais difícil e doloroso responder (a si mesmo e aos outros) por que alguém continuava pobre mesmo sendo bom, inteligente ou capaz nessa nova era meritocrática. [...]

Não faltou quem estivesse disposto a responder a essa pergunta em nome dos pobres durante os séculos XIX e XX. Para um certo eleitorado que fazia muito alarde, estava claro (e havia provas científicas) que os pobres deviam sua situação a sua própria estupidez e degeneração.

Com a ascensão de uma meritocracia econômica, os pobres deixaram de ser descritos, em alguns setores, como 'desafortunados', alvo da caridade e da culpa dos ricos, e passaram a ser descritos como 'fracassados', alvo justo de desprezo aos olhos de indivíduos fortes que se fizeram sozinhos, que não eram inclinados a sentir vergonha de suas mansões nem choravam lágrimas de crocodilo por aqueles de cuja companhia eles escaparam. (BOTTON, 2005, p. 88-89)

De acordo com Botton (2005), a principal crítica à sociedade meritocrática é que ao acreditarmos em uma sociedade na qual aqueles que merecem chegar ao topo chegam, por dedução e de uma forma negativa, acreditamos que aqueles que mereceriam chegar ao fundo também chegam, ou seja, a posição social na vida deixa de parecer acidental e sim merecida, enquanto o fracasso pessoal e profissional parece bem mais implacável. Mas o que é possível entender como sucesso, para além de uma noção central da ideologia em questão, e que nos EUA e no Brasil se pode / deve dizer / mostrar como um discurso (efeito de sentido) pré-construído e funcionando como se fosse óbvio ou comum a todos e em qualquer tempo?

\section{A MERITOCRACIA E A SOCIEDADE DE CONSUMO}

A meritocracia é a ideologia segundo a qual as classes menos abastadas, mas com talento, energia e habilidade podem chegar ao topo da hierarquia social, alcançando momentaneamente o desejo de status.

Nos Estados Unidos, Botton (2005, p. 86) afirma que, durante o Governo Kennedy, surgiram leis assegurando "uma justa oportunidade ao sucesso", como a "Lei do Pagamento Igual (1963), a Lei dos Diretos Civis (1964), a Lei de Oportunidades Iguais no Emprego (1964), a Lei dos Americanos Idosos (1965), a Lei de Discriminação por Idade no emprego (1967) e a Lei dos Americanos com Incapacidade Física (1990).”

No Brasil, essa "justa oportunidade ao sucesso" é assegurada pela Constituição Federal de 1988: art. $7^{\circ}$, XXX; art. 22 e Lei no. 10.406/02 (CC); art. $7^{\circ}$, XXXI ; art. 230 e Lei $\mathrm{n}^{\mathrm{o}}$ 10.741/03 (Estatuto do idoso); art. $7^{\circ}, \mathrm{XXX}$; art.23,II, art. 203, IV,V; e art. $224 \mathrm{e}$ 227.

É possível levar em conta a materialidade histórica das línguas do sujeito que, em ambos os países, abre-se ao equívoco, pois a língua é capaz de falha e a história reclama sentidos (ORLANDI, p. 102-103). Em outras palavras, a ordem do discurso jurídico, 
expressa também no texto da mídia, por exemplo, antes do que igualar cidadãos (indivíduos), interpela-os em sujeitos que adquirem identidade sendo divididos por sentidos que recebem unidade na legislação, seja nos Estados Unidos, seja no Brasil.

É, por um lado, o caso de "pagamento", "direitos civis", "oportunidades no emprego", "idosos", "discriminação por idade no emprego" e "incapacidade física", e as ocorrências similares em nosso país. Por outro lado, tais sentidos, ainda que pareçam significar o mesmo em ambos os países, na estrutura da língua, mobilizam outros sentidos, deslocando os sujeitos que rompem os limites do que é ser pago, cidadão, empregado, idoso, discriminado por idade no emprego ou incapaz fisicamente.

O sujeito cidadão (empregado, trabalhador, idoso e / ou deficiente) é convocado em sua língua inglesa (primeira língua de importância no mundo globalizado) ou portuguesa (língua de nossa colonização) a fazer parte desse universo simbólico ou responde a interpelação do Mercado que o convoca como sujeito do sucesso (PAYER, 2005, p. 11-13), sob um aparente sentido inequívoco e uno. Sem que se queira estender muito sobre essa questão, note-se que, nos EUA existe o sistema de Segurança Social (PORTAL US EMBASSY, 2018) que é mais um complemento a outras rendas arcadas pelo trabalhador - poupança ou demais investimentos, plano de saúde e seguro de vida pagos pelos cidadãos ou pela empresa que os emprega, sem obrigatoriedade e dependendo da condição financeira de cada um - do que um serviço de seguridade ou previdência social público, amplo e complexo como o nosso.

\section{A ideologia meritocrática e o discurso da meritocracia social}

Conforme Botton (2005), a abertura do serviço público a exames competitivos na Grã-Bretanha, em 1870, estimulou a adoção desse procedimento em outros países. A ideologia meritocrática promove o crescimento de serviços na sociedade, esse discurso (ORLANDI, 1999) do progresso é possível, pois um número maior de pessoas passa a ter acesso a maiores oportunidades de trabalho e educação.

A meritocracia pode desvincular o poder público dos laços de parentesco (nepotismo) e do corporativismo, com exceção dos cargos de comissão e contratos temporários previstos na Constituição Federal brasileira, graças à consideração de que nem todos os herdeiros seriam pessoas competentes ou bons administradores.

No Brasil, entretanto, o procedimento do Concurso Público é exigência constitucional desde 1988 nos termos do inciso II, art. 37, mas a desvinculação entre poder público e laços de parentesco não é plena, pois a Constituição também se refere a cargos políticos e de livre nomeação e exoneração, que, de fato, são os de mais alto escalão (geram maior desejo de status social), mais bem remunerados e responsáveis por decisões políticas e econômicas no país. Mesmo assim, a Meritocracia é utilizada na Sociedade de Consumo como fonte de motivação para o sucesso profissional, aumento da produtividade do trabalhador, reconhecimento no meio acadêmico e empresarial, mas também nas relações amorosas e políticas, entre outras (PORTAL TALK VÍDEO, 2009).

Para as empresas brasileiras que enfrentam grande competitividade e pressão por lucros, por exemplo, identificar, motivar e conferir mérito a talentos pode enfraquecer a ligação entre poder público, laços de parentesco e o corporativismo ainda existentes. 
Por ser uma ideologia, a meritocracia visa aos interesses de uma classe dominante e suas instituições sociais, além de poder servir como instrumento de alienação. A inversão de valores na religião cristã é um exemplo de alienação fundamentada na teoria meritocrática, pois a Riqueza criticada e condenada pelo Catolicismo, na Religião Protestante transformou-se em uma prova de que o seu dono seria detentor do Mérito em adquiri-la, e que seu esforço por conquistá-la seria uma bênção aos olhos de Deus, uma vez que a longo prazo, a riqueza só vem para o homem de moral (BOTTON, 2005).

A meritocracia busca desvincular totalmente as conquistas financeira, intelectual e moral do homem de sua condição social, pois os pobres teriam as mesmas oportunidades dos ricos, já que "o prestígio e os empregos bem pagos podem ser garantidos somente com base com base na inteligência e na capacidade de uma pessoa" (BOTTON, 2005, p. 87), e os fracassados mereceriam o próprio fracasso.

A ideia central da meritocracia na atualidade, de que os Ricos mereceriam o Sucesso alcançando status social elevado, enquanto os Pobres mereceriam Fracasso social, gera a falta de fraternidade e caridade entre os seres (paradoxo do Cristianismo que busca o amor agape desinteressado, "dádiva"). Nesse sentido, o rico já não se sentiria "obrigado" a auxiliar os necessitados, e a própria ciência humana darwinista em biologia é usada para provar que os mais fortes sobrevivem, podendo-se considerar que os pobres deviam sua situação a sua própria estupidez e degeneração (BOTTON, 2005).

\section{O CONSUMIDOR HEDONISTA: ALGUNS EFEITOS DE SENTIDO DA MERITOCRACIA}

A ideologia da sociedade meritocrática impõe o desejo de status social (BOTTON, 2005), como uma moeda invisível que atém o olhar do indivíduo aos olhos da sociedade, uma obsessão contemporânea por meio do poder de compra e do sucesso profissional.

Status Anxiety traduzido como Desejo de Status (BOTTON, 2005) simboliza a ansiedade ou angústia do status social, pois as causas dessa angústia humana não residem no grau de desigualdade social do mundo moderno, mas sim em sua própria natureza mais igualitária. Esse desejo de status não se encontra apenas abaixo da linha da pobreza, pois o sucesso, por maior que seja não remedeia o problema, trazendo a necessidade de mais sucesso.

O desejo de status manifesta-se como uma insegurança sobre o próprio valor individual. Mas o status social nem sempre foi uma expressão direta do poder econômico, pois há exemplos históricos como Esparta na Antiguidade ou as Cruzadas na Idade Média, quando apenas os atos militares conferiam status.

Nas sociedades ocidentais atuais, entretanto, status social significa, sobretudo, dinheiro.

\section{Aspectos motivacionais ao consumo: realização pelo prazer estético, equilíbrio emocional e desejo em falta}

O Consumidor Hedonista (CAMPBELL, 2001) necessita potencializar o Prazer em suas experiências; seu gozo com o consumo não se dá somente por produtos, mas sim, sobretudo, por meio de experiências agradáveis, memoráveis. Campbell (2001) considera que as experiências do sujeito da sociedade de consumo (ou do mercado capitalista) são a busca de prazer e a busca de controle emocional. 
No que se refere à experiência da Busca de Prazer, para o consumidor hedonista, o processo de compra deve ter um aspecto satisfatório. Por sua vez, em Busca de Controle Emocional, o angustiado (desejante do status social) precisa reafirmar sua autoestima com recursos que lhe faltam naturalmente (lógica platônica) ou que ele possa potencializar (lógica spinozista para Campbell), e os quais são quase sempre artificiais. Trata-se de adornar o corpo do sujeito ou fazê-lo "ser" de outra forma, por meio de recursos antinaturais, como plásticas corporais, próteses e implantes, e também se trata de adquirir bens comprados, fazer o sujeito ser reconhecido pela capacidade de "ter", roupas, acessórios, joias, veículos, imóveis, dentre outros. O gozo do sujeito consumidor hedonista, seu sucesso, se dá sob essas duas experiências, ainda que o indivíduo (cidadão, sujeito de mercado, do texto da mídia) seja rico ou pobre e faça compras planejadas ou por impulso, seja comedido (consumidor, sujeito dito normal) ou compulsivo (consumista, sujeito dito patológico), na tensão entre prazer e desprazer.

Para Campbell (2001, p.90), "o prazer não é tanto um estado do ser quanto uma qualidade da experiência". Em outros termos, a busca do prazer envolve tanto necessidades de existência quanto de auto realização (comida, arte, entretenimento etc.) em equilíbrio (potência) e em assimetria (falta). Em outros termos, o valor do "sucesso" do sujeito consumidor hedonista não é um fim em si mesmo e sim um processo tanto de construção do prazer estético (ser é ficar belo, com intervenções e adornos), quanto de controle emocional (ter status, consumir o que se imagina relacionado à sua condição social).

O Consumismo contemporâneo manifesta a necessidade do sujeito de "sonhar acordado" (day dreaming). Tudo se passa como se, quanto maior o poder de compra, maior o "sucesso" profissional (ser / ter valor de / no mercado). Novamente, nota-se que o "ser" no mundo da sociedade de consumo ou de mercado confunde-se com o "ter": computadores de última geração e carros de luxo apontam o sucesso financeiro de seus proprietários. Mas também poderiam ser citadas relações amorosas e profissionais "bemsucedidas", tensionadas entre a busca de prazer e o controle emocional do sujeito.

\section{CONCLUINDO?}

Há remédio para os males do desejo de status e do consumismo? Sofremos do mal do desejo de status, a incerteza em relação à posição social, e do mal do consumismo que dele provém.

Cinco são as Causas que provocam o desejo de status, conforme a teoria bottoniana: a falta de amor, o esnobismo dos outros, as expectativas elevadas demais, a estrutura meritocrática da sociedade e a dependência de fatores externos para a conquista do sucesso profissional. Também há, segundo o autor, cinco Remédios que, embora não sejam capazes de extinguir por completo esse mal, ajudam a controlá-lo e a tolerá-lo (equilíbrio emocional do sujeito): a filosofia, a arte, a política, o cristianismo e a boemia mais indicados para o sujeito angustiado por não estar no topo da hierarquia social e não receber o devido reconhecimento por suas realizações.

No entanto, é possível dizer que não há soluções milagrosas, pois é preciso relativizar o valor do sucesso e mostrar que a vida é mais do que ser bem-sucedido e obter prazer por meio do poder de compra ou do sucesso profissional. Dito de outro modo, somos seres finitos que sonham acordados (criam expectativas ideais), mas o sucesso econômico não é a única medida do valor de uma pessoa, e sim a sensibilidade artística, 
a amizade, o sorriso, experiências felizes de nossa história de vida que o dinheiro não pode comprar. Nesse sentido, a ideologia meritocrática é questionada com base no sentido de consumidor hedonista (supostamente bem sucedido, com valor pelo sucesso profissional, tal como a dita classe rica), cujo controle emocional pode ser tensionado pelo prazer estético (com seu corpo, adornos e bens) na busca pelo desejo de status social (ser sujeito / cidadão / do mercado globalizado / consumidor e ter emprego / profissão / bens).

Antes que sugerir recomendações infalíveis e de tentar esgotar o estudo do tema, pretende-se ter levantado aspectos fundamentais do pensamento sobre o discurso da meritocracia social, ou efeitos de sentido como a imposição do desejo de status ao sujeito da sociedade moderna de consumo, a ansiedade ou angústia do sujeito contemporâneo e a insegurança com o suposto valor do indivíduo, na relação com o capital (dinheiro) que materializa esse desejo em falta.

\section{REFERÊNCIAS}

BOTTON, A. de. IV. Meritocracia. Em: BOTTON, A. Desejo de Status. Rio de Janeiro: Rocco, 2005.

. Alain de Botton. Disponível em http://www.alaindebotton.com/. Acesso 10 ago. 2014.

CAMPBELL, C. A ética romântica e o espírito do consumismo moderno. Rio de Janeiro: Rocco, 2001.

ORLANDI, E.P. Do Sujeito na História e no Simbólico. Em: ORLANDI, E.P. Discurso e Texto: formação e circulação dos sentidos. Campinas: Pontes, 2001. p. 99-108.

. Análise de discurso: princípios e procedimentos. Campinas: Pontes, 1999.

PAYER, M.O. Linguagem e sociedade contemporânea. Sujeito, mídia, mercado. RUA, v. XI, Campinas, LABEURB, UNICAMP, 9-26, 2005.

PÊCHEUX, M. (1975). Semântica e discurso: uma crítica à afirmação do óbvio. Campinas: Editora da Unicamp, 1995.

PORTAL TALK VIDEO. Alain de Botton: uma filosofia de sucesso mais bondosa e delicada. Em: Ted Global 2009, 16, 51, filmado em julho de 2009. Disponível em https://www.ted.com/talks/alain_de botton_a kinder_gentler_philosophy_of_success?language =pt-br. Acesso em 10 de agosto de 2014.

PORTAL US EMBASSY. Previdência Social - Embaixada e Consulados dos EUA no Brasil. Disponível em https://br.usembassy.gov/pt/u-s-citizen-services-pt/previdencia-social/. Acesso em 27 de julho de 2018.

\section{Agradecimentos}

À professora Maria Cláudia Tardin Pinheiro, do MBA em Estratégias e Ciências do Consumo, na Escola Superior de Propaganda e Marketing - ESMP Rio, e aos colegas Leonardo Dobrowsky (UFRJ) e Guilherme Rapp (ESPM), que motivaram a escrita do presente artigo. Agradeço muitíssimo a todos.

Artigo recebido em: junho de 2018.

Aprovado e revisado em: setembro de 2018.

Publicado em: dezembro de 2018. 


\section{Para citar este texto:}

PEREIRA, Rosane da Conceição. Prazer estético e controle emocional ou causa do desejo de status: o discurso da meritocracia social e o consumidor hedonista. Entremeios [Revista de Estudos do Discurso, ISSN 2179-3514, on-line, www.entremeios.inf.br], Seção Estudos, Programa de Pós-Graduação em Ciências da Linguagem (PPGCL), Universidade do Vale do Sapucaí (UNIVÁS), Pouso Alegre (MG), vol. 17, p. 175-181, jul. - dez. 2018.

DOI: http://dx.doi.org/10.20337/ISSN2179-3514revistaENTREMEIOSvol17pagina175a181 